\title{
Homogeneous, surfactant-free gold nanoparticles encapsulated by polythiophene analogues $\dagger$
}

\author{
Cheng-Hsuan Lai, ${ }^{a}$ I-Che Wu, ${ }^{a}$ Chia-Cheng Kang, ${ }^{a}$ Jyh-Fu Lee, ${ }^{b}$ Mel-Lin Ho ${ }^{a c}$ \\ and Pi-Tai Chou*a
}

Received (in Cambridge, UK) 19th December 2008, Accepted 6th February 2009

First published as an Advance Article on the web 25th February 2009

DOI: $10.1039 / \mathbf{b 8 2 2 8 2 7 b}$

\begin{abstract}
The synthesis of nanocrystal-polymer nanocomposites is reported, in which 2-(2-ethoxyethoxy)ethoxy modified polythiophene serves as the protecting group for dispersion and homogeneous size distribution of the nanoparticles, showing potential of this polymer-based material in optoelectronics and microelectronics.
\end{abstract}

The photophysical properties and electrical conductivity of conjugated polymers have drawn much attention since Shirakawa et al. ${ }^{1}$ revealed the electrically conducting phenomenon of polyacetylene in 1977. Unlike other types of polymers, conjugated polymers exhibit conducting and/or semiconducting behaviors and thus serve as promising candidates for development of light emitting diodes, photovoltaic, field effect transistor, and thermoelectric materials. ${ }^{2-7}$ However, the devices composed of conjugated polymers are still lower in efficiency compared to those prepared from traditional inorganic materials. One current approach to expand the feasibility of polymer-based devices lies in the design and synthesis of nanocomposites incorporating a polymer matrix and nanocrystals. ${ }^{8,9}$ For example, in 2005, Carroll's group reported a new class of P3HT-based, organicinorganic hybrid heterojunction photovoltaic solar cells. ${ }^{10}$ It was expected that the high electron mobility of the additive nanocrystals could partially overcome the charge-transport limitations. Unfortunately, addition of surfactant to stabilize the nanocrystals might lead to unexpected damage on film morphology of the conjugated polymer and consequently the hindrance of electrons during the transportation process.

It is thus of interest to consider the preparation of nanocrystals free from surfactants/ligand. Unfortunately, the absence of surfactant is severe for dispersion of nanoparticles, and aggregation is unavoidable. One route to circumvent this obstacle is via chemical modification, in which both polymers and nanoparticles are first modified with complementary functional groups. ${ }^{11-14}$ Subsequently, they are allowed to react with each other under mild conditions. However, experimental steps embarking on this method are rather complicated, and aggregation of nanoparticles is still a problem en route to

\footnotetext{
${ }^{a}$ Department of Chemistry and Instrumentation Center, National Taiwan University, Taipei 106, Taiwan.E-mail: chop@ntu.edu.tw

${ }^{b}$ National Synchrotron Radiation Research Center, Hsinchu 300. Taiwan

${ }^{c}$ Department of Chemistry, Soochow University, Taipei 111, Taiwan. E-mail: chop@ntu.edu.tw

$\dagger$ Electronic supplementary information (ESI) available: Experimental section, Figs. S1-S5. See DOI: 10.1039/b822827b
}

polymer bound nanocomposites. In order to improve e.g. the electrical properties of polymers for device applications, the search of new synthetic routes that ensures the dispersion of nanoparticles in the polymer matrix is an emergent issue.

We report herein a facile process to prepare homogeneous, surfactant-free metal nanoparticles encapsulated by polythiophene analogues. In contrast to previous attempts that ubiquitously utilized blending process between the as-prepared polymers and nanoparticles, we use poly(alkoxythiophene) to chelate the designated metal ions. These polymer bound metal ions are then applied as precursors and metal ions are reduced in situ to obtain the corresponding poly(alkoxythiophene)bound well dispersed nanoparticles with homogenous size distribution. Detailed syntheses, characterization and applications are described as follows.

A qualitative illustration of the synthetic route is depicted in Scheme 1. In brief, 2-(2-ethoxyethoxy)ethoxy-modified polythiophene (P3EEET, $M_{\mathrm{n}}$ : 8890, PDI: 1.29) was synthesized via polymerization of dibromo[2-(2-ethoxyethoxy)ethoxy] thiophene monomer (see ESI $\dagger$ ). Subsequently, while stirring, various amounts of $\mathrm{HAuCl}_{4}$ solution $\left(0.05 \mathrm{M}\right.$ in $\left.\mathrm{H}_{2} \mathrm{O}\right)$ were added to the solution containing P3EEET (4 mg P3EEET in $5 \mathrm{ml}$ acetonitrile) to allow chelation. The $\mathrm{Au}(\mathrm{III})$ ion chelation process was allowed to proceed for $\sim 2 \mathrm{~h}$ before the characterization.

Fig. 1(b)-(d) show the absorption spectra of P3EEET with 20,40 and $80 \mu \mathrm{L}$ added $\mathrm{HAuCl}_{4}(0.05 \mathrm{M})$ solution, respectively. Fig. 1(a) also shows the absorption spectrum of

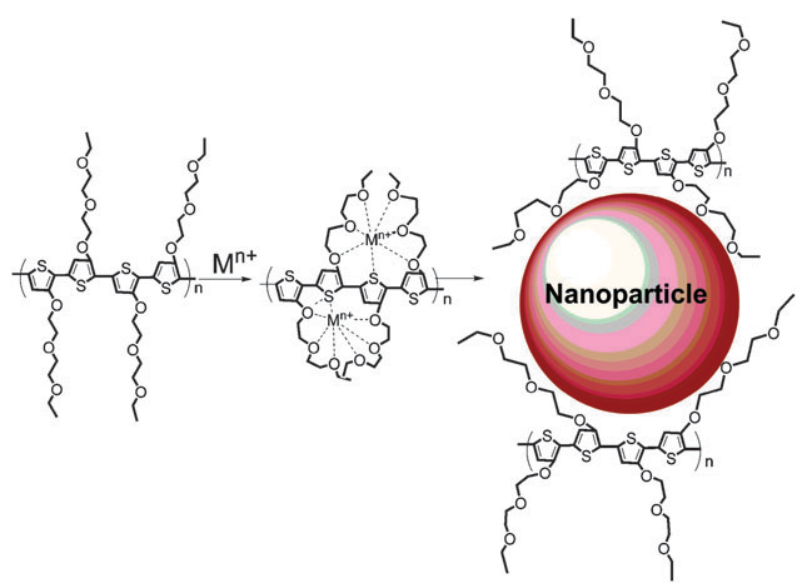

Scheme 1 A qualitative illustration of the polymer backbone conformation with metal ion complexation and the polymernanoparticle nanocomposite. 


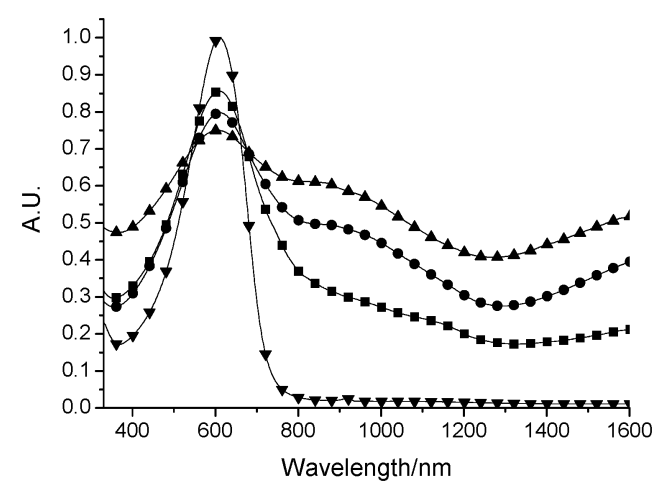

Fig. 1 Absorption spectra of P3EEET reacted with different concentrations of $\mathrm{HAuCl}_{4}$ in acetonitrile: (a) $0 \mathrm{uL}$ ( $\mathbf{\nabla}$ ); (b) $20 \mu \mathrm{L} \mathrm{HAuCl}_{4}$ (ם); (c) $40 \mu \mathrm{L} \mathrm{HAuCl} 4$ (○); (d) $80 \mu \mathrm{L} \mathrm{HAuCl}_{4}(\mathbf{\Delta})$. Note that the P3EEET samples containing $\mathrm{Au}(\mathrm{III})$ ion were allowed to react for $2 \mathrm{~h}$ before measuring the absorption spectra.

$\mathrm{Au}(\mathrm{III})$-free P3EEET in a control experiment. For the $\mathrm{Au}(\mathrm{III})$ free P3EEET, the lowest-lying absorption band, showing a maximum at $610 \mathrm{~nm}$, can be reasonably ascribed to the backbone $\pi \rightarrow \pi^{*}$ transition of the polythiophene units. Upon addition of $\mathrm{HAuCl}_{4}$ followed by aging for $2 \mathrm{~h}$, a new absorption band gradually appeared at $950 \mathrm{~nm}$, accompanied by a decrease of the $610 \mathrm{~nm}$ band. This phenomenon is reminiscent of the ionochromic effect documented in previous literature, ${ }^{15-19}$ and the variation of absorption is mainly due to the conformational perturbations of polythiophene molecules.

The roles of metal ions in the reaction system incorporating polythiophene analogues have been reported. ${ }^{16,18}$ We accordingly propose there exists a non-covalent, electrostatic (ion-dipole) interaction among $\mathrm{Au}(\mathrm{III})$ ions, oxygen atoms on ether side chains and sulfur atoms of P3EEET (see Scheme 1), which restricts the free rotation around the thiophene-thiophene bond. As a result, the backbone of P3EEET is driven from a non-planar conformation to a planar one. As for conjugated polymers, there is a correlation between the electronic structure and backbone conformation, such that the variation of absorption shown in Fig. 1 is mainly due to the conformational perturbations of polythiophene molecules. The increase of the $950 \mathrm{~nm}$ band implies that $\mathrm{Au}(\mathrm{III})$ ions induce an evolution which transforms disordered P3EEET molecules to the ordered, planar conformation, compared with the Au-free P3EEET samples.

To provide another spectral evidence for the interaction between P3EEET and Au(III) ion, X-ray absorption near-edge structure (XANES) data was performed at the Au $\mathrm{L}_{\mathrm{III}}$ edge as shown in Fig. S1 (ESI $\dagger$ ). After adding $\mathrm{HAuCl}_{4}$ into the P3EEET solution, the resulting data of the prepared sample is consistent with the presence of cationic gold formally represented as $\mathrm{Au}(\mathrm{III})$ ion, as evidenced by the position of the absorption edge at $11919 \pm 0.5 \mathrm{eV}$, characteristic of $\mathrm{Au}(\mathrm{III})$ ion. The result supports the viewpoint that the $950 \mathrm{~nm}$ band in the absorption spectrum is caused by the conformation change of P3EEET but not the e.g. redox reaction between $\mathrm{Au}(\mathrm{III})$ ion and the polymer backbone. The rise of the absorption at $>1300 \mathrm{~nm}$ in Fig. 1 could be rationalized by taking the polaron-bipolaron mechanism into consideration. ${ }^{20,21}$ The polaron-bipolaron model predicts a metallic-like optical transition with a band gap down to the near infrared region.
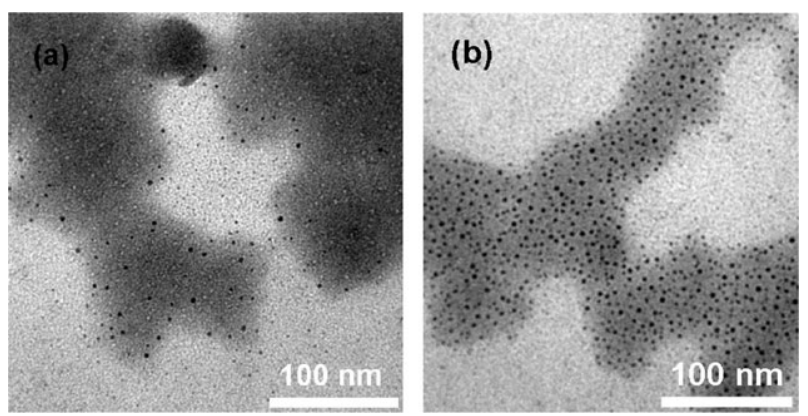

Fig. 2 TEM image of P3EEET-Au nanocomposites with different amounts of $\mathrm{HAuCl}_{4}(0.05 \mathrm{M})$ : (a) $20 \mu \mathrm{L}$; (b) $80 \mu \mathrm{L}$.

We then made further attempts to synthesize the P3EEET-Au nanocomposite using Au(III) doped P3EEET as a precursor. In this approach, ascorbic acid was added as a reducing agent to the Au ion-P3EEET system and the solution was aged for $24 \mathrm{~h}$. The progress of reaction can be visualized via the color changes from dark green to deep blue. The resulting product was dried and then washed with deionized water. Unreacted gold ions and uncapped gold nanoparticles would be washed out because of poor solubility of P3EEET in $\mathrm{H}_{2} \mathrm{O}$. TEM images of nanocomposite with $20 \mu \mathrm{L}$ and $80 \mu \mathrm{L}$ $\mathrm{HAuCl}_{4}(0.05 \mathrm{M})$ solution are shown in Fig. 2(a) and (b), respectively. The Au nanoparticles are well dispersed in the polymer matrix, and the size distribution is quite homogeneous, indicating excellent capping ability of P3EEET. The corresponding histogram of size distribution and EDS analysis for the Au nanocomposite are depicted in Fig. S2 and S3 of ESI. $\dagger$ TEM analysis of the diameters of 200 relatively uniform nanoparticles in Fig. 2(b) yielded an average diameter of $4.0 \pm 0.5 \mathrm{~nm}$.

Previously, a number of groups have synthesized $\mathrm{Au}$ or Ag nanoparticles by using polypyrrole, polyaniline and poly(3-octylthiophene)s (P3OT) as protecting groups. ${ }^{22-24}$ The reported procedures, unfortunately, involved complicated experimental protocols. Some convenient procedures have been reported to synthesize polythiophene-Au nanoparticle composites $^{25,26}$ by reducing $\mathrm{Au}(\mathrm{III})$ ions with thiophene, followed by forming polymer in situ. However, due to the lack of molecular weight controlling process, it was difficult to manipulate the molecular weight of the as-prepared polythiophene. In comparison, in this study, because of the confined molecular weight distribution of polythiophene, regioregular polythiophene with PDI $<1.3$ could be obtained. ${ }^{27}$ Note that PDI is critical while considering the conductivity of polymers.

Fig. 3 shows the absorption spectra of Au-P3EEET nanocomposites with different amount of $\mathrm{Au}(\mathrm{III})$ ion added. In comparison to the absorption spectrum of $\mathrm{Au}(\mathrm{III})$ ion capped P3EEET, a new absorption band obviously appears at around $575 \mathrm{~nm}$ for the as prepared Au-P3EEET nanocomposite. It is reasonable to assign this peak to the surface plasma resonance (SPR) band of $\mathrm{Au}$ nanoparticles, the origin of which is well documented in the literature. ${ }^{28}$ Slight deviation from the typical SPR of $\sim 525 \mathrm{~nm}$ for the similar size $(3.0-4.5 \mathrm{~nm}) \mathrm{Au}$ nanoparticles in solution may indicate that the SPR band is highly sensitive to the local environment such as interparticle spacing and ligands, etc. in addition to size and shape. ${ }^{29,30}$ 


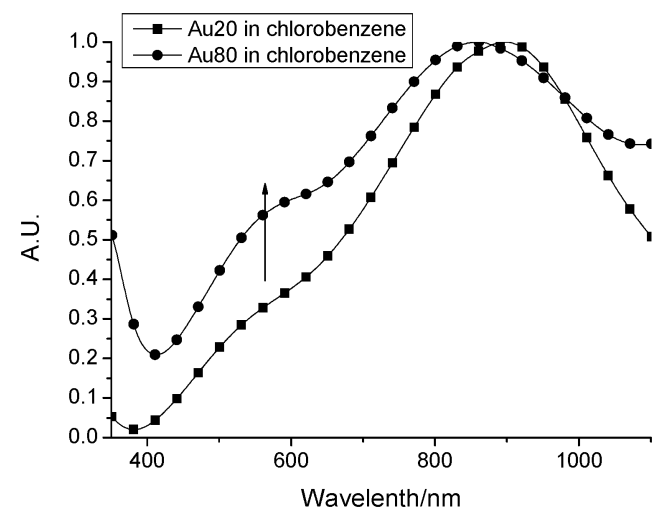

Fig. 3 Absorption spectra of Au-P3EEET nanocomposites with different amount of $\mathrm{Au}$ in acetonitrile: (a) $20 \mu \mathrm{L} \mathrm{HAuCl}_{4}$ (ם); (b) $80 \mu \mathrm{L} \mathrm{HAuCl}{ }_{4}(\bullet)$.

We then performed a comparative experiment by first synthesizing Au nanoparticles via reduction of $\mathrm{Au}(\mathrm{III})$ using citric acid. Interestingly, upon mixing the as-prepared $\mathrm{Au}$ nanoparticles with P3EEET, no evidence of the $575 \mathrm{~nm}$ band was observed and the Au nanoparticles were found to precipitate and aggregate at the bottom of the reaction vial. This finding further supports the indispensability of in situ synthesis for obtaining P3EEET capped $\mathrm{Au}$ nanoparticles. To examine the role of P3EEET, a set of experiment has been performed, in which $80 \mu \mathrm{L}$ of $\mathrm{HAuCl}_{4}(0.05 \mathrm{M})$ was added into $5 \mathrm{~mL}$ acetonitrile. Subsequently, ascorbic acid was quickly injected into the solution. During the reaction, a brown precipitate at the bottom of vial appeared, which is believed to be due to the aggregation of gold nanoparticles. Hence, the presence of P3EEET is indispensable for obtaining monodispersed gold nanoparticles.

From the viewpoint of applications, the as-synthesized Au-free P3EEET and Au-P3EEET samples were spin coated on indium tin oxide conductive glass (ITO), and the electrical properties measured and plotted as $I-V$ curves. As shown in Fig. 4, comparing to that of the Au-free P3EEET, the increase of $\mathrm{Au}(\mathrm{III})$ concentration in the precursor leads to a decrease of the inflection voltage of conductivity. This result may be rationalized by the facilitation of electrons hopping through metal islands in the Au nanocomposite. Raising the density of the nanoparticles could reduce the Schottky barrier formed between the nanocomposite film and electrode. Hence, the ability of electron injection from electrode to nanocomposite is significantly improved.

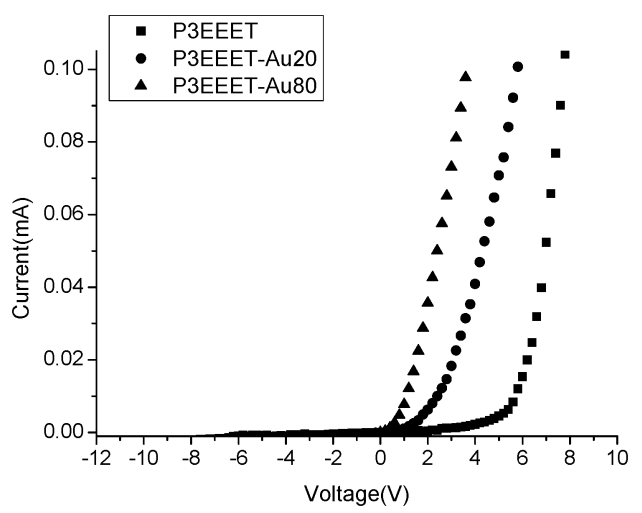

Fig. $4 \quad I-V$ characteristic curves of different thin films.
In conclusion, a new approach to synthesize Au nanocrystal bound polymer nanocomposites is reported, in which P3EEET serves as the encapsulation agent. The results reveal, for the first time, the good dispersion and homogeneous size distribution of the nanoparticles in the polymer matrix. In a preliminary examination, the electrical properties of the assynthesized nanocomposite revealed a substantial improvement of charge injection compared with that of neat P3EEET. Since the length of alkoxy side chains can be fine-tuned, this protocol, in theory, can be expanded to prepare size dependent metal NP-polymer or even semiconductor NP-polymer nanocomposites, in which the nanomaterials are derived from the corresponding metal (semiconducting metal) cation precursor. The results presented herein thus demonstrate the potential of alkyloxyl modified polythiophene-based nanocomposites in the field of optoelectronics and microelectronics devices.

\section{Notes and references}

1 H. Hirakawa, E. J. Louis, A. G. Macdiarmid, C. K. Chiang and A. J. Heeger, J. Chem. Soc., Chem. Commun., 1977, 578.

2 Y. Wu, P. Liu, S. Gardner and B. S. Ong, Chem. Mater., 2005, 17, 221.

3 W. Ma, C. Yang, X. Gong, K. Lee and A. J. Heeger, Adv. Funct. Mater., 2005, 15, 1617.

4 G. Lu, H. Usta, C. Risko, L. Wang, A. Facchetti, M. A. Ratner and T. J. Marks, J. Am. Chem. Soc., 2008, 130, 7670.

5 F. C. Krebs and H. Spanggaard, Chem. Mater., 2005, 17, 5235.

6 M. Reyes-Reyes, D. L. Carroll and K. Kim, Appl. Phys. Lett., 2005, 87, 083506.

7 F. Yakuphanoglu and B. F. Senkal, J. Phys. Chem. C, 2007, 111, 1840.

8 W. U. Huynh, J. J. Dittmer and A. P. Alivisato, Science, 2002, 295, 2425 .

9 W. J. E. Beek, M. M. Wienk and R. A. J. Janssen, Adv. Funct. Mater., 2004, 16, 1009.

10 K. Kim and D. L. Carroll, Appl. Phys. Lett., 2005, 87, 203113.

11 Q. Zhang, T. P. Russell and T. Emrick, Chem. Mater., 2007, 19, 3712.

12 J. Xu, J. Wang, M. Mitchell, P. Mukherjee, M. Jeffries-EL, J. W. Petrich and Z. Lin, J. Am. Chem. Soc., 2007, 129, 12828.

13 J. Heo, D. S. Kim, Z. H. Kim, Y. W. Lee, D. Kim, M. Kim, K. Kwon, H. J. Park, W. S. Yun and S. W. Han, Chem. Commun., $2008,6120$.

14 J. Shan and H. Tenhu, Chem. Commun., 2007, 4580.

15 E. E. Sheina, S. M. Khersonsky, E. G. Jones and R. D. McCullough, Chem. Mater., 2005, 17, 3317.

16 I. C. Wu, C. H. Lai, D. Y. Chen, C. W. Shih, C. Y. Wei, B. T. Ko, C. Ting and P. T. Chou, J. Mater. Chem., 2008, 18, 4297.

17 T. M. Swager and M. J. Marsella, J. Am. Chem. Soc., 1993, 115, 12214.

18 M. H. Xu, H. C. Zhang and L. Pu, Macromolecules, 2003, 36, 2689.

19 I. Lévesque and M. Leclerc, Chem. Mater., 1996, 8, 2843.

20 D. T. Mcquade, A. E. Pullen and T. M. Swager, Chem. Rev., 2000, 100, 2537.

21 J. L. Brédas and G. B. Street, Acc. Chem. Res., 1985, 18, 309.

22 E. Pintér, Z. A. Fekete, O. Berkesi, P. Makra, Á. Patzkó and C. Visy, J. Phys. Chem. C, 2007, 111, 11872.

23 Z. Peng, L. Guo, Z. Zhang, B. Tesche, T. Wilke, D. Ogermann, S. Hu and K. Kleinermanns, Langmuir, 2006, 22, 10915.

24 M. M. Oliveira, E. G. Castro, C. D. Canestraro, D. Zanchet, D. Ugarte, L. S. Roman and A. J. G. Zarbin, J. Phys. Chem. B, 2006, 110, 17063.

25 B. R. Panda and A. Chattopadhyay, J. Colloid Interface Sci., 2007, 316, 962 .

26 M. M. Oliveira and A. J. G. Zarbin, J. Phys. Chem. C, 2008, 112, 18783.

27 S. McCullough, R. D. Iovu, M. C. Sheina, E. E. Gil and R. R, Macromolecules, 2005, 38, 8649.

28 M. M. Alvarez, J. T. Khoury, T. G. Schaaff, M. N. Shafigullin, I. Vezmar and R. L. Whetten, J. Phys. Chem. B, 2006, 101, 3706.

29 M. D. Malinsky, K. L. Kelly, G. C. Schatz and R. P. V. Duyne, J. Phys. Chem. B, 2001, 105, 2343.

30 G. Xu, Y. Chen, M. Tazawa and P. Jin, J. Phys. Chem. B, 2006, 110, 2051. 